\title{
Knowledge, attitudes, and perceptions of dairy farmers regarding antibiotic use: Lessons from a developing country
}

\author{
Iman Dankar, ${ }^{1} \oplus$ Hussein Hassan, ${ }^{2 *} \odot$ and Mireille Serhan ${ }^{1 *}$ (이 \\ ${ }^{1}$ Department of Nutritional Sciences, Faculty of Health Sciences, University of Balamand, Al Koura, PO Box 100, Tripoli, Lebanon \\ ${ }^{2}$ Nutrition Program, Department of Natural Sciences, School of Arts and Sciences, Lebanese American University, Beirut, PO Box 13-5053, \\ Chouran 1102 2901, Lebanon
}

\begin{abstract}
In lower- and middle-income countries, uncontrolled use of antibiotics is causing antimicrobial resistance, affecting both animal welfare and public health. Meanwhile, studies on antibiotic use in these countries are limited. A crucial step to limit the spread of antimicrobial resistance (AMR) is to examine the use of these drugs and identify its determinants. The aim of our study, the first of its kind in Lebanon, was to assess dairy farmers' knowledge and awareness of antimicrobial use (AMU) and AMR. For this, 18 farmers from different regions, educational backgrounds, experience levels, and herd sizes were interviewed. Results showed that owners of larger farms were more aware of AMU and AMR, and trying to implement preventive actions, whereas nonsystematic antimicrobial use was prevalent among the smaller farms. Mastitis and laminitis were the most treated diseases, and antibiotics used were oxytetracycline, penicillin, streptomycin, and florfenicol. Overall, antibiotic use was found as a preventive measure and a treatment of nonbacterial diseases. Irregular uses were linked to easy access of farmers to antibiotics, interrupted relations with veterinary authorities, and lack of self-assessment and inspection. Lebanese dairy farmers and owners reported feeling disadvantaged in their local trade field, facing illegal competition and unauthorized farms and industries, and lacking support from the government. Training and awareness programs must be implemented, and policies and regulations must be set, to reduce antibiotic use and hinder the spread of AMR in Lebanon.
\end{abstract}

Key words: milk, farms, antimicrobial resistance, Lebanon

Received July 7, 2021.

Accepted October 24, 2021.

*Corresponding authors: hussein.hassan@lau.edu.lb and mireille. serhan@balamand.edu.lb

\section{INTRODUCTION}

The effectiveness of antimicrobials as requisite preventive means for decreasing morbidity and transience of bacterial infectious diseases cannot be ignored. Before the introduction of antimicrobials in animal agriculture in the late 1940s, many contagious diseases were untreatable (Prescott, 2019). Additionally, antimicrobials are prescribed as a triggering agent for animal health and productivity (Saini et al., 2012). However, continuous concern exists about the development of antimicrobial resistance (AMR) and the threat it might pose for both animal and human health, resulting in restricted efficacy of existing drugs administered on farms as well as in human hospitals (Jones et al., 2015). Various national and international bodies have found the spread of resistant microbial pathogens to be directly associated with progressive antimicrobial misuses (Kassaify et al., 2013; WHO, 2020). In particular, antimicrobial misuses are directly linked to farmers' practices, including antimicrobial overuse, suboptimal use, and noncompliance with the prescribed duration. One major concern is that these antimicrobials are often the same drug classes used in human medicine (Prestinaci et al., 2015). Van Boeckel et al. (2015) reported that approximately 63,000 tons of antimicrobials are globally administered per year in food animals, and by 2030 it is projected to increase by $70 \%$ in livestock. Aside from the top consumers (China, the United States, and Brazil), the largest relative increase of livestock antimicrobial uptake is expected to take place in developing countries, such as Nigeria and Indonesia, where an increase of more than $200 \%$ is estimated (Van Boeckel et al., 2015). Moreover, in Lebanon, Kassaify et al. (2013) have confirmed the presence of resistant strains of major pathogens against 2 widely used antibiotics, gentamycin and streptomycin, in raw milk samples, which could be imputed to uncontrolled antimicrobial practices among farmers. As a result, restricting antibiotic usage in farm animals can be an effective strategy for limiting the spread of antimicrobial resistance. This was addressed via the 
Food and Agriculture Organization (FAO) 2021-2025 action plan, which suggested the following approaches: increasing stakeholder awareness and engagement, strengthening surveillance and research, enabling good practices, and strengthening governance and sustainable allocation of resources (FAO, 2020).

To date, many studies have addressed farmers' attitudes with regard to antimicrobial use (AMU) in different countries worldwide, such as in France (Dernburg et al., 2007), the Netherlands (Speksnijder et al., 2017), Denmark (Oliveira et al., 2018), Sudan (Eltayb et al., 2012), and Peru (Redding et al., 2014). All of these studies aimed at aligning better actual use of antibiotics with medical recommendations. Only a few research studies (Buller et al., 2015; Swinkels et al., 2015; Fischer et al., 2019) have assessed the reasons behind these behaviors. Farmers' attitudes and practices do not develop in isolation; they are a result of the intermingling tensions of the economic, social, and political regulative structures that shape each society (Fischer et al., 2019). Farmers' actions are country-specific, as they are affected by the farmer's own experience, veterinarian advice, antibiotics supplier's scope, interactions with other farms, policies, surveillance, traditions, and economic and political stability.

In Lebanon, dairy products are considered an essential part of the Mediterranean diet, with an average intake among adults ranging between $243.1 \mathrm{~g} / \mathrm{d}$ (Raad et al., 2014) and $350.5 \mathrm{~g} / \mathrm{d}$ (Farhat et al., 2016), which is considered to be very close to that of neighboring Mediterranean countries (Kabrite et al., 2019). Mostly, Lebanese dairy farms are family based; they extend from large farms associated with manufacturers of dairy products, to small-owned farm businesses, with the Bekaa governorate accounting for the majority (44\%) of the farming land (Saadeh, 2016). Local production is more than enough to cover demand, but it is facing serious competition, especially from unauthorized local producers and smuggled lower-quality and cheaper dairy products from Syria. In Lebanon, policies and surveillance programs are absent, attention to biosecurity measures is lacking, and research is tightly limited in the dairy farming sector. Availability of data on AMU can aid in interpreting patterns and identifying the roots for risk assessment of AMR, in addition to supporting decision makers in developing national and international policies and control measures (Saini et al., 2012).

That is why the aim of our study, the first of its kind in Lebanon, was to address farming practices from a wider context through an in-depth study of Lebanese dairy farmers' backgrounds, experience and educational levels, knowledge and awareness of AMU and AMR, re- lationships with veterinarians, and significant challenges. In particular, our research objectives were to assess farmers' awareness, attitudes, and knowledge regarding antibiotic use, to evaluate farmers' understanding of AMR, and to inspect their practices in dairy farming.

\section{MATERIALS AND METHODS}

\section{Study Design}

A semi-structured interview focusing on antibiotic use in dairy farms was conducted among 18 farmers or manufacturers of dairy products from different regions in Lebanon, and with different educational and social backgrounds. Data collected reflected the diversity in conditions of dairy farming in Lebanon.

\section{Selection of Farmers}

The list of all manufacturers of dairy products in the country was obtained from the Lebanese Ministry of Industry (Beirut). The total number of manufacturers of dairy products in the country was 200 and all owners were male. Manufacturers were classified according to their geographic location in the 8 governorates of Lebanon (Akkar, Beirut, Bekaa, Nabateye, Baalbeck, Mount Lebanon, North Lebanon, and South Lebanon). Of these 200 manufacturers of dairy products, 50 had no contact information. The other 150 were approached to reach a sample size of 20 . Recruited manufacturers of dairy products were mainly located in Bekaa and Mount Lebanon, where the majority of dairy farms are (64\%). The selected manufacturers of dairy products were invited to participate in this research via telephone due to COVID-19 pandemic restrictions. The contacted manufacturers of dairy products were first asked whether they have their own farm, and, if not, they were requested to provide the contact information of the farmers from whom they collect the milk. In total, we obtained 18 respondents, 15 of which were dairy farm owners and 3 were farmers who did not own their farms. Table 1 summarizes the overall characteristics of the participating dairy farms.

\section{Qualitative Semi-Structured Interview Approach}

The aim of the structured interview approach was to describe the wide possible circumstances of AMU, based on the grounded theory approach, rather than to assess it quantitatively (Corbin and Strauss, 2012). The length of each interview $(1-1.5 \mathrm{~h})$ encouraged authentic discussion. The interviewer made sure to ask all the questions, even if she had assumptions in 
Dankar et al.: ANTIBIOTIC USE IN LEBANON

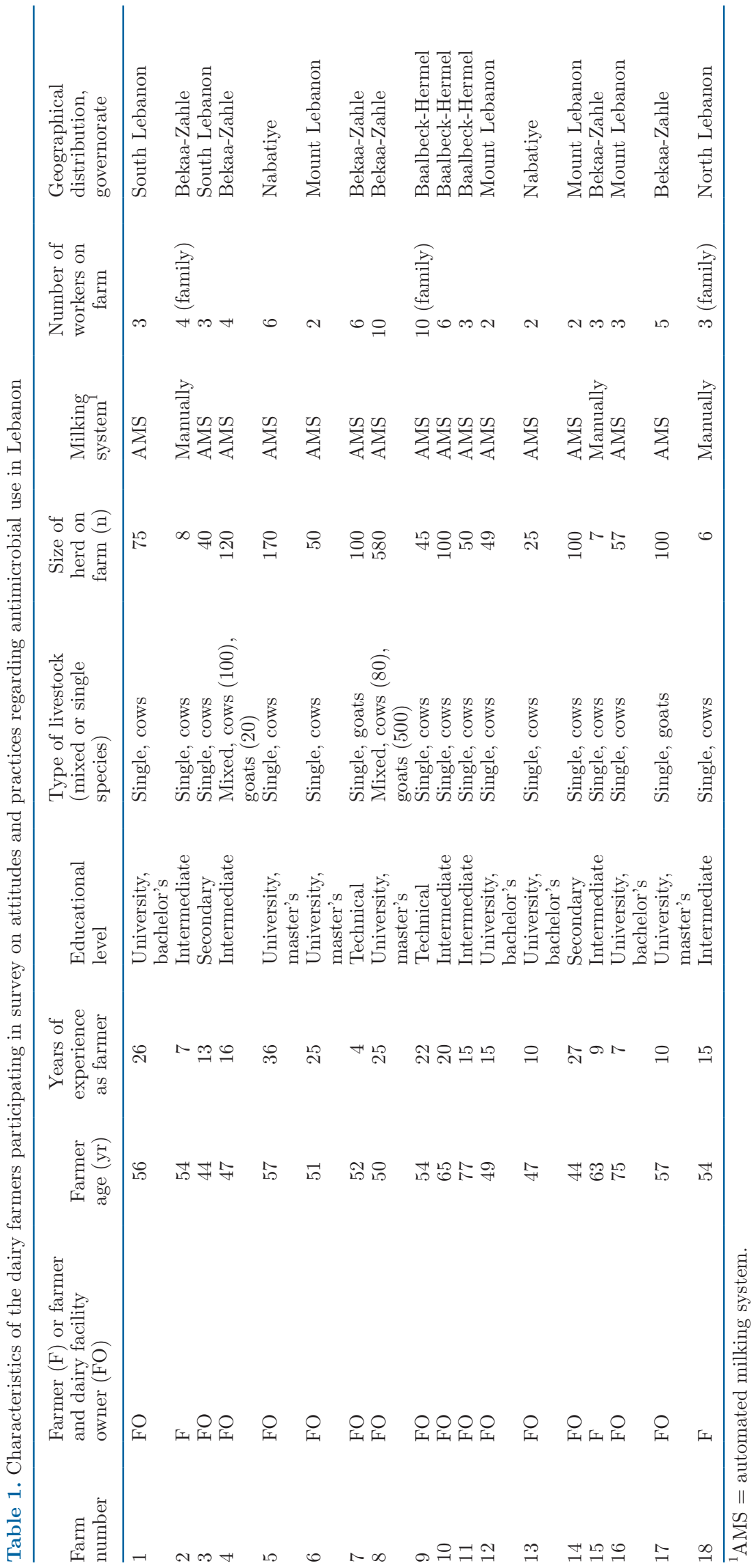


mind for particular questions. The interviewer did not have any personal or professional ties with any of the participants. In contrast to quantitative questionnaires with closed-ended questions, qualitative methods allow understanding of sociological and economic motives by permitting unforeseen replies (Oliveira et al., 2018). The interviews were conducted according to an interview guide structured into 5 main themes: (1) personal demographics and workplace (farm) characteristics, (2) knowledge of antibiotics, (3) animal health and welfare, (4) practices regarding AMU, and (5) knowledge about AMR. The interview guide was a flexible platform that supported open follow-up questions. Some detailed questions under each theme were also involved. The setup of questions designed for the interview were the result of an extensive literature review of up-to-date articles concerned with the practices of dairy farmers regarding AMU. The questions were shaped to evaluate the circumstances of the local farmers and to understand the reasons behind their farm practices. Interviewees were permitted to express themselves and expand their points of view on issues that they found relevant to the subject; sometimes they were provided some choices to more effectively direct the focus of the question and prevent deviation from the topic. With the informed consent of the interviewees, interviews were recorded and fully transcribed to avoid an analytical interpretation. Respondents were assured that the aim of this investigation was to map their thoughts and practices regarding AMU, and not to judge them. Ethical approval to conduct the study and to contact farmers was obtained from the institutional review board at the University of Balamand, Al Koura.

Interviews were conducted between March and May 2020. Interviewing new farmers stopped when a theoretical saturation in the topics discussed was attained, meaning that no further theoretical development could be achieved by conducting additional interviews (Corbin and Strauss, 2012). The final sample consisted of 18 dairy farms. Questions were in Arabic, the official language of the country. Recorded answers were then translated into English. Findings from other studies regarding antibiotic uses and practices by farmers were considered in developing the interview guide questions (Alhaji and Isola, 2018; Fischer et al., 2019). Interview questions were first piloted on 5 farmers and dairy farm owners.

\section{Data Analysis}

Interview transcripts were read very carefully and coded inductively by the first author, using the qualitative data analysis approach to identify emerging themes
(Bernard, 2011; Corbin and Strauss, 2015). Coding involves labeling relevant words, phrases, or actions in the transcript and categorizing them into particular themes, with subthemes within these (Bryman, 2011). Interview texts that were coded for the same themes were reviewed attentively and in order. The validity of the qualitative research is determined by the power and soundness of the arguments provided, as well as by the thoroughness of reporting the techniques in the study, and the re-coding and comparison of data between the researchers (Mays and Pope, 2000). To that aim, the coding was double-checked for uniformity by the 3 researchers.

At a later stage, the themes were explored using frame analysis (Virkki et al., 2015), exploring the views of the farmers according to the particular themes. To be specific, themes refer to a certain category, such as farmers' antimicrobial practices, and frames refer to how these themes are discussed, such as antimicrobial misuses, proper uses, and factors inside or outside the farmers' control. Reading through the codes and focusing on how that particular subject is described helped in identifying frames. The codes were re-read to ensure that the frames identified were accurate and that nothing was missed. During the analysis, data saturation was achieved whenever no new information was produced, and the same codes were emerging and being described in similar ways (Guest et al., 2006).

\section{RESULTS}

\section{Overview of the Farms}

All farmers $(\mathbf{F})$ and farm owners (FO) worked full time in farming. In addition, all farms regularly hire farm workers except 3 , which rely entirely on family members. It was observed that all dairy facility owners were also farm owners and farmers at the same time, taking care of their own animals. Although this resulted in particularly hard work, it was also described as a potential benefit for animal health and welfare:

"I believe it is better to use my own experience and education to take care of the details of the farming system and tools; being on a daily basis in my farm allows discovering things early if they aren't right." (FO 6, Mount Lebanon)

Only one farm, farm 8, which was established in 1950, was inherited from parents, and now its owners represent the third consecutive generation. The other farms and dairy industries were all established by the owners themselves, who mostly possess a great deal of expe- 
rience built on their age and farming-based working years. Other FO rely also on their educational background in monitoring their farms, being holders of a university degree in the field of agriculture, forestry, or animal sciences, and by compiling knowledge from attaining exchangeable, international visits and courses (Table 1):

"After earning my master's in animal sciences, I established routine visits with different farms in Holland, Germany, and France and took some courses regarding proper farming management in Greece. I also attended different conferences about animal husbandry, antibiotic uses, and alternative medical care ... It is extremely important to try to manipulate what you experienced outside at your own farm, since most European countries are advanced in terms of animal health care and proper monitoring of farm management." (FO 8, Bekaa-Zahle)

It was also observed that most farms rely on imported types of breeds (mostly from Germany and Holland), which farmers believed had much better physical and health states than the local breeds. Few farms owned a local herd (baladi), both of which were solely goat farms. Farms had a relatively small number of animals in the herd (between 6 and 9) compared with several herds ranging between 50 and 580 animals with FO farms. Consequently, milking for $\mathrm{F}$ farms was performed manually, whereas FO farms all used automated systems.

\section{Knowledge of Antibiotics}

The majority of the respondents believed that antibiotics should be administered only to treat infections in animals. Others noted that antibiotics are also used to promote growth, prevent infections, and help animals recover quickly. Moreover, the majority of the farmers interviewed stated that they understand that antibiotics are considered misused only when they are delivered as an overdose for livestock. They linked this to the possibility of passing antimicrobial residues to humans through the consumption of contaminated milk and meat. Only some farmers stated that antibiotics are misused at both overdose and underdose administration.

When asked what they thought were the advantages and disadvantages of reducing AMU, most farmers mentioned that the major advantage would be reducing AMR in animals and subsequently improving public health. Others declared that advantages included less withholding of milk and meat, revamping the image of the dairy industry, and improving animal health.
By contrast, concerns about reducing AMU were easily sensed by the farmers. It was clear from the interviews that the majority of the farmers believed that antimicrobials showed no adverse effects on animals and they were more worried about the health of sick cows and the possibility of recovering from their diseases without using antibiotics, a situation that is strongly linked to traditional practices and knowledge background:

"No, we cannot reduce the use of antibiotics; this is not possible . . . There would be a lot of disadvantages; all cows would be susceptible to severe illnesses, and we cannot recover out from these issues without using antibiotics, definitely. This also means more intensive work from the farmer taking care of the herd . . . Meanwhile we cannot think of it." (FO 10, Baalbeck)

Only FO 8 stated that reducing the usage of antimicrobials on the herd would have no disadvantages at all; in contrast, it would imply merely positive effects on the farm and would increase the productivity of the herd and that of the dairy industry as well:

"Less antibiotic uses on farm means less withdrawal periods of milk. Therefore, more milk would be incorporated in the production of the dairy industry. Additionally, our herd is less exposed to antibiotics, their immune system is boosted, and they enjoy better health welfare." (FO 8, BekaaZahle)

\section{Animal Health and Welfare}

In general, based on the interviews, all farmers agreed that cows are much more susceptible to diseases than goats and require more intensive care. Dairy goat farmers and farm owners were more relaxed in relation to the health status of their herds and less concerned about medication use and AMU. Hence, the focus was directed toward cow health management. Several factors characterize proper health management, which farmers consider essential to follow: (1) the appropriateness of the geographical location, (2) hygienic aspects of the farm, (3) the type and amount of food that the cow ruminates, and (4) the good husbandry culture of the farmer. According to farmers, especially those who owned a large herd, it is necessary to have flat land with few inclines, to avoid decayed hooves, hoof inflammation, or "foul foot" in cows. Maintaining proper sanitation is important to reduce introduction of disease to the cattle, such as keeping the barn clean, making sure that the land below the cow is totally dry, 
and spraying the farm with pesticides on a weekly basis to diminish the amount of penetrating insects that might transmit many diseases to the cows. Some of the interviewees indicated that they had great competency in aseptic cleaning protocols:

"For us, cleaning is a sacred act ... thorough sanitization is carried out on a daily basis for the cows, inside the farm, and its surroundings. We have made a contract with a leading pest control company in Lebanon, for a weekly insect and hygienic inspections ... additionally, the workers perform a medical checkup every month since the farmer himself might be the transmission guidance of some diseases . . . and now that we are facing the COVID-19 pandemic, all workers are asked to wear masks and gloves as precautions." (FO 13, Nabateye)

However, these routines were not totally practiced by other farms; for example, FO 10 stated that the place where the cows sleep should be cleaned continuously but it is not necessary to clean the cow itself:

"Cows are capable of self-cleaning; no need to bother cleaning them." (FO 10, Baalbeck)

Furthermore, FO 6 highlighted that good management of the farm includes not only cleaning of the cows and their surroundings but also preserving a free space for the cows to avoid being confined too closely together. Farmers also stated that most of the diseases experienced by herds arise from malnutrition and irregular feeding problems. Primarily, the type and quality of the fodder should be well controlled. Each farmer prepares a specific mix of plants that suits their herd. Generally, a mixed fodder contains barley, wheat, and fermented corn. Otherwise, the fodder is imported from outside, mainly from Egypt, Jordan, and Syria. However, the farmer should be careful not to deviate significantly from the type of fodder presented to the herd even among the different seasons. Farmers explained that because the cow would be accustomed to a certain quality, any nonconformity might result in indigestion and cause acidity. The problem might even intensify to left displaced abomasum, a disorder widely encountered among lactating cows in Lebanese farms, which requires surgical intervention to resolve. Accordingly, it is important to respect the quality, quantity, and time interval for cow feeding and rumination:

"You know what is worse, sometimes farmers feed their cattle with their food leftovers, and conse- quently the type of the bacterial flora inside the abdomen responsible for proper digestion and consecutive milk production would change. So, we are left with indigestion problem and less productivity . . . adding to that, transfer of the food from one abdomen to the other would be slowed, and fungus might accumulate inside the abdomen, leaving the cow to suffer more ... it is really dangerous, and such irresponsible acts are merely unacceptable." (FO 5, Nabateye)

On the contrary, it was found that the type of feeding differs according to the geographical location, land availability, and economic capability of the farmer. Farmer F18 claimed that they rely solely on extensive feeding, with cows moving across the roads of the village, grazing some wild plants, grasses, and bushes:

"Those dominant wide fields are primarily located in Bekaa and Baalbeck. Here, in my town, I am obliged to free up the cows to graze what they find along the streets. Previously, I could not afford buying fodder ... a and now, under the economic crisis Lebanon is facing, it is 6 times as expensive, compared to what it was 3 months ago!" (F18, North Lebanon)

\section{Practices Regarding Antimicrobial Use}

The most common health conditions in dairy cows reported by Lebanese farmers, and which caused the most productivity losses, were laminitis (hoof inflammation) and mastitis (udder inflammation), followed by respiratory infections. The major cause of these diseases is often bacteriological, and the severity of inflammation might differ. It is recommended that, postlactation, cows should be prevented from sitting on the ground, because the udder would be still open and may become contaminated by pathogens, which consequently causes inflammation. Moreover, antimicrobials are not always considered as first-choice therapy, as only severe inflammations are to be treated with antibiotics. For instance, subclinical mastitis could be treated by having the affected quarter dried off (Fischer et al., 2019). Overall, not all the farmers appeared aware of AMU and how to treat and prevent common diseases. Some farmers (the owners who hold a higher education degree, and the owners of larger farms) possessed this key knowledge. In addition, some farmers indicated that they use antibiotics as preventive care, where they administer antibiotics to a cow that has given birth, to protect it from a possible microbial infection or metritis (uterine inflammation). Others stated that they deliver 
antibiotics to their herd especially in the summer season, in which animals are more subjected to diseases and viruses due to elevated temperatures.

"When a cow is feeling bad, not eating as usual and has some fever on, we provide it with antibiotics, as a method to speed up its recovery. I cannot bother a lot with its illness . . . But we don't provide antibiotics to any cow that is pregnant." (FO 11, Baalbeck)

When asked to report about the most frequently used antimicrobials, all farmers mentioned penicillin and neomycin, among other popular anticipated antibiotics such as sulfonamides, oxytetracycline, erythromycin, florfenicol, amoxycillin, and tylosin. The most common practice was administering antibiotics via intramuscular injection. The majority of the farms indicated that they have access to those antibiotics by purchasing them from veterinary pharmacies when needed and only if prescribed by a veterinarian. Moreover, most of these farmers reported that they never treated their animals with antibiotics themselves and instead let the veterinarian administer the treatment. By contrast, the remaining farmers stated that they always keep some antibiotics stored in the farm's stock, to have quick access to antibiotics during emergencies. Those farmers also admitted that they do use antibiotics without the recommendation of the veterinarian. They relied on their experience, believing that through their practical years, they have gained enough knowledge to enable them to specify what type of antibiotic and when and at what dosage it should be administered to their herd. Only when the case becomes too hard to resolve, they might contact a veterinarian:

Interviewer: "So, let us assume an antibiotic that you have tried as a treatment for your cow does not work well; do you go for an alternative antibiotic that you have previously tried without even referring to a veterinarian?"

Respondent: "Well . . First, let me tell you that most of the antibiotics I have used on my cows along my 20 years work in dairy farming have performed a good job up to 60 to $70 \%$. Yes, in some cases where we face some drawbacks and not a total recovery, I go on using another antibiotic or base the treatment on a mixture of two without a need to bother asking a veterinarian. For example, I use penicillin for treating laminitis. If penicillin was not enough to cure the case, I combine it with oxytetracycline. Now if our several attempts did not succeed, as in some rare cases, we might then refer to a veterinarian's advice, but we try to make this our last option." (FO 10, Baalbeck)

In an attempt to better understand the farmer-veterinarian relationship, farmers were asked about the periodic time range for routine field visits from their veterinarians. The majority of the farmers responded that they might consult a veterinarian's advice via phone calls, but they rarely have a site visit from a veterinarian. Some farmers asserted that they had routine visits from the veterinarians almost once per year, and some farmers mentioned that they had veterinarians' consultancy on site visits at a frequency of approximately once per 6 mo, both of which are considered a relatively long period:

"You should know that the choice for calling a veterinarian, specifically for site consultancy, is strongly influenced by a cost-benefit calculation, particularly with reference to the economic crisis we are facing in Lebanon; it would be so money consuming to bring a veterinarian to check for a sick calf, or a cow expressing little changes in its eating habits. We try to work out minor issues at our own . . . But . . . once you have built good connections with your veterinarian, you could solve a lot of your problems via phone calls. I try to tell them what I see on my cows, and in turn I take into consideration the advice they deliver . . . By this I avert the payment of the veterinarian's bill and the taxi driver bill as well." (FO 12, Mount Lebanon)

It was clear from the interviews that the relationship with veterinarians was not central for most of the farmers. Farmers claimed the absence of any regulations that specify the use of antibiotics by the farmer or the farmer-veterinarian relationship. Therefore, no rule dictates that antibiotics should be purchased only with a veterinary prescription, nor that specific antibiotics should be given only to critical cases. Farmers highlighted that the situation is so alarming that the solution lies in the farmer's awareness, knowledge, and consciousness. Only a few farmers relied solely on the medical expertise of a veterinarian and on their daily presence at their farm. It is important to state that those farms were among the large farms in this interview, and their owners possessed a degree in farming or animal husbandry:

"Veterinarian's consultation and his daily checkup is a primary standard. Only the veterinarian has 
the right to prescribe and decide when medication is needed . . . To assure this I have made a fixed, full-time contract with a veterinarian at our farm ... My son is also studying veterinary medicine abroad in France; he is in the third year now . . . I get a lot from his advice in improving and setting my farm into the best conditions." (FO 1, South Lebanon)

Another major point that was discussed with interviewees was how they dealt with the milk produced by cows under antibiotic treatment or during the antibiotic withdrawal period. When asked about what governs their decisions, all the farmers emphasized that their measures are shaped by economic and sociopolitical factors. All farmers reflected the lack of any appreciation or support from the government, especially the smaller farms that were struggling to face the hyperinflation of the Lebanese lira. All farmers were concerned about antibiotics hindering the production process, due to their capability of killing lactic acid bacteria (important in fermenting yogurt culture), causing economic losses to the farm and the manufacturers of dairy products. However, some farmers were less troubled than others about this issue, expressing that they have established alternatives for using this milk in production processes:

"What we try to do in order to compensate this economic loss, is to direct the production of milk with antibiotics toward cheese formation, since antibiotics do not affect the process of cheese making, nor its sensory or aromatic properties. Moreover, nowadays with the help of the veterinarian, we are using antibiotics that are effective on the cow but have a very minimal effect on the fermenting milk to yogurt process, and we are achieving higher production than before." (FO 10, Baalbeck-ElHermel)

A few other farmers were in line with FO 10, believing that their business exists to generate revenues eventually. In turn, they would distribute this milk in separate gallons to small manufacturing dairy shops that would make it into cheese or sell it as raw milk directly to people, noting that in Lebanon, especially in rural areas, people still purchase raw milk and cheeses directly from the farmer.

Although all farmers were worried about the production process, many of them also expressed their concern about antibiotic residues in milk products and their consequent effects on consumers. For this, each farmer suggested different alternatives for handling milk with antibiotic residues, without using it in the production process. In fact, most of the suggestions were directed toward feeding this milk to calves during the course of antibiotic treatment or during the withdrawal period. Other farmers argued against this idea, believing that antibiotics would persist inside the calf's body and meat. Some of their different recommendations and practices were as follows:

"I definitely do not recommend and do not allow milk with antibiotic residues to be fed to calves at my farm; there is a high risk that the calf's body would develop antibiotic resistance when fed with that milk . . Instead, we discharge that milk into the sewage system." (FO6, Mount Lebanon)

"Milk with antibiotic residues is not delivered to calves; it is used as a biomaterial land compost instead." (FO 14, Mount Lebanon)

"We have established our own milk spoilage refinery system at the farm; it is about extracting the water out from the milk for recycling while utilizing the remaining part for compost. Moreover, I have newly introduced to my industry an innovative machine in collaboration with the European Union, which I have invested a lot in, capable of detecting the antibiotic resistance inside the milk, not only the presence or absence of antibiotics." (FO8, Bekaa-Zahle)

\section{Knowledge About Antimicrobial Resistance}

When the topic of AMR was addressed, half of the interviewed farmers urged the necessity of further highlighting this issue in Lebanon. However, it was clear from the interviews conducted that most farmers lack knowledge about AMR and its resulting consequences. Ten farmers believed that the use of antibiotics does not lead to AMR and that only their misuse (such as incorrect dosage or disrespected treatment period) would do so. Moreover, most of the farmers agreed that the effects of AMR in cows are translated as a nonresponse to microbial treatment, with a consequent extra cost in curing microbial infection:

Interviewer: "What is AMR developed by dairy cows, and what are its consequences?"

Respondent: "I think AMR is when a cow gets accustomed to a certain antimicrobial, after its repeated use as a treatment ... So we go on and switch for another kind of antimicrobial ... This might lead to an extra cost of treatment." (F 15, Bekaa-Zahle) 
Respondent: "For me, AMR is summarized by its adverse effects on humans . . . For example, when a person consumes dairy products from a sick cow that was under antibiotic treatment, and where withdrawal period was not respected, that person might one day catch a fever or inflammation and then get a medicine similar to the one delivered to the cow ... Now, this antibiotic won't be effective in his body, because it has already developed resistance against it . . . You see, it is really dangerous!" (FO 14, Mount Lebanon)

Unfortunately, not all the farmers were aware of the threatening effects of antibiotics misuse, whereas some farmers agreed that the problem with AMR in humans depends only on incorrect use of antibiotics for humans and not for animals. Several more farmers admitted that they have no idea what the term "antimicrobial resistance" refers to, and they lacked any knowledge about its consequences on animals or humans. So, when asked questions about AMR, they simply answered, "I don't know."

\section{DISCUSSION}

To the best of our knowledge, this is the first qualitative study investigating AMU in dairy cattle in Lebanon. The farmers interviewed presented a mix in relation to farm size (conventional small and large farms; some were among the largest in Lebanon), ownership (family farm or a farm coupled with a dairy product manufacturing company), history, and location. Most of the farms were established by the owner himself, as a family farm along with the dairy product manufacturing company, with his sons or brothers.

Notably, the average age of all the interviewed farmers was high (Table 1), which reflects the general case of the dairy farmers in Lebanon. In fact, agriculture plays a relatively minor role in Lebanon, contributing about $5 \%$ of the gross domestic product; this is due to the lack of governmental support of the agricultural sector (FAO, 2021a) and its focus more on the services sector, which accounts for around $86.36 \%$ of the gross domestic product (O'Neill, 2021). This overall trend has decreased the interest of new generations in agriculture, leading to their deviation more toward business and economic trade, leaving mostly the older, more traditional generation responsible for the farming sector.

The practices of antibiotic use in dairy farms were diverse with regard to the educational backgrounds and knowledge levels of farmers and farm owners. In our study, many FO held a university degree, including a master's degree in animal sciences, agriculture, or forestry, and were the respondents with the highest experience level (ranging from 10 to 36 years of experience). However, some FO and all F (although they have good experience in farming) had reached only an intermediate level of study. The level of education was not consistent within a certain demographic region. Yet, it played an important role in shaping the knowledge level regarding AMU among farmers and their subsequent practices. Those with a less academic background were found to put less focus on antibiotic misuse and its practices. It was common to find farmers who stock antibiotics at their farms, prescribe antibiotics on their own, and use milk under antibiotic treatment or during the withdrawal period in the manufacturing processes of cheeses. A second group of farmers keep antibiotics at their farms but try to refer to a veterinarian before prescribing them to their herd, and those farmers were not willing to use milk with antibiotic residues in subsequent processing, but deliver it to calves instead. A third limited group of farmers hire a veterinarian at their farm on a daily basis; this was ultimately observed among the largest farms. The owners of the latter farms refuse to feed their calves with milk mixed with antibiotic residues; instead, they discharge it to compost, sewer, or recycling systems. Similarly, Ozturk et al. (2019) found that antibiotic knowledge level was significantly higher among farmers with a postgraduate degree than high school and primary school graduates or those with less formal education. Eltayb et al. (2012) also concluded that higher levels of education were significantly associated with higher levels of knowledge of AMR and disease among farmers in Sudan.

The fact that some of the farmers still show noncompliance with antimicrobial withdrawal periods leads to high concentrations of antimicrobial residues in dairy products. In turn, this stimulates the emergence of new pathogens with AMR genes (Speksnijder et al., 2017). Noncompliance by dairy farmers could also be explained by the fear of financial loss that may arise from discarding milk during withdrawal period. With reference to the results generated in the present study, many farmers are not willing to throw their milk away, but direct it to cheese production in order not to lose it. It is important to note that currently the Lebanese pound has faced a tremendous collapse with respect to the American dollar. Lebanon is suffering from an unprecedented economic crisis, which has been an added burden on all the dairy farmers, especially the ones with small farms and limited budget.

This study also revealed high practices of selfadministration of antimicrobials, in addition to those who prescribe antimicrobials by themselves, which is critical and can lead to underdosing or overdosing in 
dairy cattle, without perceiving whether the antimicrobial course was completed or not. Unfortunately, the majority of the farmers stated that antimicrobial misuse is when delivered only at an overdose to sick cows, reflecting the attitude of preferring to provide an underdose of an antimicrobial (to stop delivering the medicine once the cow shows signs of recovery), believing this to be one of their good practices. Significantly, underdosing was reported by many scientists as being the main reason for dangerously developing AMR (Speksnijder et al., 2017). Pathogens exposed to subinhibitory concentrations of the antimicrobials will lead to more survival of bacterial populations in that animal and generating an advanced resistance to the antimicrobial (Bolinger and Kathariou, 2017).

The scarcity in accessing veterinary services and the ease of obtaining antimicrobials from human pharmacies and drug suppliers without veterinarian prescription is another reason for uncontrolled AMU in Lebanese dairy farms. In this study, farmers showed a trend of developing their own system of reference, without any veterinary advice, a way of gaining more independence toward managing their animal health. This could be due to lack of strict government regulations guiding antimicrobial sales for animal use in Lebanon. The practice of over-the-counter purchase has been reported by several authors, especially in developing countries such as Nigeria (Alhaji et al., 2018). Moreover, the lack of any governmental support pushes farmers to deviate in their choices in making financial compromises on healthcare and welfare.

Additionally, it was clear in this study that antimicrobials are used for therapeutic and prophylactic purposes in some dairy farms. Absence of definitive regulations leads to such irrational practices. In the case that such regulations are present, such practice means they are not properly implemented. In other words, most farmers are not aware of the emergence of AMR pathogens with use of antimicrobials as preventives (prophylactic), since pathogens would be exposed to selective pressures, forcing them to mutate or acquire pieces of DNA to become antimicrobial resistant (Lundin et al., 2008). Unfortunately, the World Health Organization (WHO) has declared that AMR is one of the top 10 global public health threats facing humanity (WHO, 2020).

As reported herein, the most identified used antimicrobials by dairy farmers were penicillin, neomycin, oxytetracycline, tylosin, sulfonamides, amoxicillin, florfenicol, and erythromycin, most of which are considered by the WHO to be critically important (amoxicillin, neomycin, furaltadone, erythromycin, gentamicin, ampicillin, and colistin) or highly important (sulfonamides, doxycycline, and oxytetracycline) for humans (WHO, 2018). Consequently, their residues in dairy products are transmitted to humans upon consumption, leading to the threat of developing AMR. In this trend, high AMR to colistin (one of the critically important antibiotics widely used in human hospitals) has recently been identified among Lebanese people (Hmede and Kassem, 2019; Osman et al., 2019). Additionally, it is reported that human consumption of milk contaminated with antimicrobials could lead to allergic reactions, cancer, alteration in intestinal flora, and development of AMR pathogens (More et al., 2012; Engdaw and Asredie, 2015).

It is noteworthy that AMR attributed to animal origin has already been investigated in Lebanon (Kabrite et al., 2019; Araj et al., 2020). Studies have reported that spread of resistant bacteria from animal-based food products to humans may be caused by direct contact or indirectly via food, water, or animal fecal application to farm fields (Marshall and Levy, 2011). Although most of the surveyed farmers believed that AMR cannot be transmitted from animal to animal in the field, results have demonstrated that workers who are in close contact with infected animals are at risk of being directly colonized with resistant bacteria (Choi et al., 2011). Most farmers in Lebanon are in close contact with animals that are confined at the respective farm, inevitably increasing the possibility of transmitting antimicrobials from animals to humans. We must also take into consideration that families of the workers would also be at a risk of infection, thereby forming a route for the spread of resistance genes into the community (Zhang et al., 2009).

Our study indicates that larger farms are more likely to remain in farming than their smaller counterparts, and that they possess a positive intention to reduce antibiotic usage and drive consumer confidence in their products. In contrast, farmers who had imposed improper dosage of antimicrobials have done so due to weak financial status and their inability to periodically contact a veterinarian. Poverty has been stated as the chief root of antimicrobial misuse in developing countries (Amábile-Cuevas, 2010; Ayukekbong et al., 2017). In addition, farmers' lack of education and low knowledge level have created an imbalanced husbandry management system. These factors combine to proliferate the threat of emergence and spread of antimicrobial pathogens. However, these issues could be addressed by increasing the knowledge of farmers through awareness, as better knowledge leads to prevention (Alhaji et al., 2018). This could be carried out by launching welldesigned campaigns targeting dairy farmers to improve preventive care in animals, which is of great importance 
to enhancing animal health, such as vaccination, which most of the surveyed Lebanese farmers stated that they follow on a regular basis. Moreover, it is crucial to highlight AMU versus antimicrobial misuses for dairy farmers and its consequent impact on public health. Basic awareness should be built periodically and on a long-term basis to be effective in changing deep-rooted practices. Different media could serve as platforms, such as radio, roadside, or television advertisements, as well as social media. Harbarth et al. (2015) have reported that strengthened awareness via mass media, especially radio, is effective at lessening antimicrobial misuse and AMR rates, provided that key messages are delivered in a continuous manner. In addition, veterinarians, specifically the public veterinarian sector, should play their role in raising awareness and ensuring that strong governmental regulations, embedded with solid implementations on judicious use of antimicrobials in food animals, are in place (Alhaji et al., 2018).

The owners of the largest farms, coupled to dairy product manufacturing companies, were educated enough and showed better practices regarding herd management and AMU. Although these dairy product manufacturers were among the major dairy product sellers in Lebanon, it is necessary to understand AMU on small farms whose farmers possess a lower level of education. Large dairy product manufacturers have the ability to examine milk before processing, whereas small dairy farms distribute raw milk directly from the farm to local customers, who still prefer to drink fresh cow milk and make their own cheeses but lack the ability to inspect for the presence of antibiotic residues in milk. Another crucial concern is the fact that small dairy farms distribute milk to many small local shops and to unlicensed small manufacturers of dairy products that lack any inspection and, in turn, sell them to markets and people. Practically, in Lebanese markets, the customer purchases either packaged dairy products having the company name, shelf life, and nutritional information, or packaged dairy products in plastic bags without any company name or other details. The latter are referred to as "baladi" products, meaning fresh and local, and they are mostly lower in price and more common. Baladi products are usually made by unlicensed industries, local shops, or local cheese makers. In fact, this practice is widespread in Lebanon in rural and urban areas, making it an issue of prime public health concern.

It is clear that farmers' attitudes and actions reflect a wider social structure rather than an individual behavior produced in isolation. How a farmer or dairy owner performs and what they perceive is merely steered by the political and economic context in which they live.
This was indeed reported and interpreted by all of the farmers' answers. As exemplified by Fischer et al. (2019), agricultural policies and milk prices shape the ways farmers can practice their farming, and these become personified in farmers' practices and perspectives. Moreover, Robinson (2017) concluded in his study that diseases affecting the herd and the factors affecting their control cannot be considered in isolation of the wider social, economic, and environmental contexts within which they are situated. Additionally, the deflation and instability that Lebanon is currently facing have pushed farmers toward more uncertain actions. With reference to the above, this study suggests that the agriculture and farming sector in Lebanon would benefit from governmental support, although limited. Jones et al. (2015) found that farmers would be more willing to reduce antibiotic use if they had a financial incentive to do so. Additionally, information resources should be strengthened to support animal health policies as well as the biosecurity measures of farmers and veterinarians (Alhaji et al., 2018).

It is worth mentioning that the results of the present study could reflect, to a large extent, the status of other developing countries, specifically those countries that share a similar culture, social background, and economic insecurities and which therefore may have similar practices. For instance, a study reported by (Obaidat et al., 2018) indicates that antimicrobials are frequently misused in dairies in Jordan; farmers independently prescribe the dose and the type of antimicrobial to their herd, and they can easily purchase antimicrobials without veterinary prescription. Additionally, the study reflected that the dairy farmers disrespected the withdrawal period, and that those practices have led to high resistance among commensal Escherichia coli toward antimicrobials of human and veterinary importance, urging the necessity of educational programs and enacting regulations toward judicious AMU in Jordan (Obaidat et al., 2018). The same scenario was conveyed by Meskini et al. (2021) in Algeria, Eltayb et al. (2012) in Sudan, and Benavides et al. (2021) in Peru, who stated that dairy farmers lack the proper knowledge of AMU and that they should be involved in a training plan associated with high surveillance to improve their farming practices. Thus, our study supports the necessity of driving national policies, forcing regulations, and launching training programs with the support of international organizations such as the WHO and FAO.

The FAO, with the WHO and the World Organization for Animal Health (OIE), are supporting countries in developing and implementing their One Health National Action Plans on AMR. The ultimate goal is to ensure sustainable use of antimicrobials to reduce AMR 
concerns, in accordance with the Global Action Plan on AMR - the world's strategy for combating the emergence and spread of AMR, which threatens many of the world's Sustainable Development Goals on health, food security, environmental well-being, and socioeconomic development (WHO et al., 2019; FAO, 2021b).

In fact, international organizations have already helped in raising awareness in Lebanon. The governmental agriculture and veterinarian sector in Lebanon have authorized the FAO to launch an awareness program on good hygienic farming practices and the prudent use of antimicrobials for Lebanese farmers in Nabateye. Moreover, the WHO, with the aid of the United Nations Environment Program, was willing to launch a training program for the dairy farmers in Bekaa and Baalbeck on the sensible use of antimicrobials and the risk factors behind the evolution of AMR. However, due to the rising pandemic and the evolving insecurity issues in Lebanon since 2019, this program was postponed. Those awareness programs are effective, and we urge that they should be implemented to judiciously restructure the practices of Lebanese dairy farmers.

Several limitations apply to this study. Telephone interviews might have driven potential information bias, provided by the farmers' answers, especially those related to proper drug use and management (e.g., following veterinarian recommendation and leaflet instructions; farm hygiene and cleaning aspects). However, the purpose of the study was explained to the farmers, and it was made clear that the authors were not going to judge famers' practices. Although the length of the interview was a positive, and allowed a lot of information to be gathered, it can be considered a limitation as well, since some of the farmers were very busy with their work. Therefore, we mentioned to the farmers that they could stop the interview at any time and resume it at a later stage. Other limitations faced in this study were poor telephone and internet connections, leading to ambiguity in receiving information. Therefore, we had to repeat questions or gently ask the farmer to repeat his response several times.

\section{CONCLUSIONS}

Our study provided qualitative data on the methods and rationales behind antibiotic use in Lebanon, which provides essential information for setting actions. It allowed diagnosing patterns of antibiotic use among a group of farms of different sizes, types, and backgrounds in the country. However, further epidemiological studies are needed to relate these findings to a wider context. Overall, larger farm owners had a higher level of education and consequently higher awareness concerning AMU and AMR patterns. Although some farmers had over 20 years of experience, they still lacked information on how to prevent diseases and deal with their variations. However, these farmers were confident about prescribing and using antimicrobials on their own. The unprecedented economic and political situation in Lebanon has forced the majority of dairy farmers to prioritize economic profit over animal welfare and public health. This study provides much-needed evidence to support decision-making for developing national policies and control measures.

\section{ACKNOWLEDGMENTS}

This study received no external funding. The authors have not stated any conflicts of interest.

\section{REFERENCES}

Alhaji, N. B., A. E. Haruna, B. Muhammad, M. K. Lawan, and T. O. Isola. 2018. Antimicrobials usage assessments in commercial poultry and local birds in North-central Nigeria: Associated pathways and factors for resistance emergence and spread. Prev. Vet. Med. 154:139-147. https://doi.org/10.1016/j.prevetmed.2018.04.001.

Alhaji, N. B., and T. O. Isola. 2018. Antimicrobial usage by pastoralists in food animals in North-central Nigeria: The associated sociocultural drivers for antimicrobials misuse and public health implications. One Health 6:41-47. https://doi.org/10.1016/j.onehlt .2018.11.001.

Amábile-Cuevas, C. F. 2010. Global perspectives of antibiotic resistance. Pages 3-13 in Antimicrobial Resistance in Developing Countries. Springer New York. https://doi.org/10.1007/978-0-387 -89370-9_1.

Araj, G. F., D. M. Berjawi, U. Musharrafieh, and N. K. E. Beayni. 2020. Activity of ceftolozane/tazobactam against commonly encountered antimicrobial resistant Gram-negative bacteria in Lebanon. J. Infect. Dev. Ctries. 14:559-564. https://doi.org/10.3855/ jidc. 12368 .

Ayukekbong, J. A., M. Ntemgwa, and A. N. Atabe. 2017. The threat of antimicrobial resistance in developing countries: Causes and control strategies. Antimicrob. Resist. Infect. Control 6:47. https:/ /doi.org/10.1186/s13756-017-0208-x.

Benavides, J. A., D. G. Streicker, M. S. Gonzales, E. Rojas-paniagua, and C. Shiva. 2021. Knowledge and use of antibiotics among lowincome small-scale farmers of Peru. Prev. Vet. Med. 189:105287. https://doi.org/10.1016/j.prevetmed.2021.105287.

Bernard, H. R. 2011. Research Methods in Anthropology: Qualitative and Quantitative Approaches. 5th ed. AltaMira Press.

Bolinger, H., and S. Kathariou. 2017. The current state of macrolide resistance in Campylobacter spp.: Trends and impacts of resistance mechanisms. Appl. Environ. Microbiol. 83:1-9. https://doi.org/10 .1128/AEM.00416-17.

Bryman, A., 2011. Mission accomplished? Research methods in the first five years of Leadership. Leadership 7:73-83. https://doi.org/ $10.1177 / 1742715010386864$

Buller, H., S. Hinchliffe, J. Hockenhull, D. Barrett, K. Reyher, A. Butterworth, and C. Heath. 2015. Systematic review and social research to further understanding of current practice in the context of using antimicrobials in livestock farming and to inform appropriate interventions to reduce antimicrobial resistance within the livestock sector. Department for Environment Food and Rural Affairs UK. Accessed Nov. 11, 2021. http://randd.defra.gov.uk/ Document.aspx?Document=12817_ReportO00558Final.pdf. 
Choi, M. J., S. K. Lim, H. M. Nam, A. R. Kim, S. C. Jung, and M. N. Kim. 2011. Apramycin and gentamicin resistances in indicator and clinical Escherichia coli isolates from farm animals in Korea. Foodborne Pathog. Dis. 8:119-123. https://doi.org/10.1089/fpd 2010.0641

Corbin, J., and A. Strauss. 2012. Basics of Qualitative Research: Techniques and Procedures for Developing Grounded Theory. 3rd ed. SAGE Publications. https://doi.org/10.4135/9781452230153.

Corbin, J., and A. Strauss. 2015. Basics of Qualitative Research: Techniques and Procedures for Developing Grounded Theory. 4th ed. SAGE Publications.

Dernburg, A. R., J. Fabre, S. Philippe, P. Sulpice, and D. Calavas. 2007. A study of the knowledge, attitudes, and behaviors of French dairy farmers toward the farm register. J. Dairy Sci. 90:1767-1774. https://doi.org/10.3168/jds.2005-223.

Eltayb, A., S. Barakat, G. Marrone, S. Shaddad, and C. Stålsby Lundborg. 2012. Antibiotic use and resistance in animal farming: A quantitative and qualitative study on knowledge and practices among farmers in Khartoum, Sudan. Zoonoses Public Health 59:330-338. https://doi.org/10.1111/j.1863-2378.2012.01458.x.

Engdaw, T. A., and T. Asredie. 2015. Antimicrobial residues in cow milk and its public health significance. World J. Dairy Food Sci. 10:147-153. https://doi.org/10.5829/idosi.wjdfs.2015.10.2.96244.

FAO (Food and Agriculture Organization). 2020. Progress report on the implementation of FAO Action Plan on Antimicrobial Resistance (AMR) 2016-2020, and the proposal for a new FAO Action Plan on AMR 2021-2025. Accessed Nov. 11, 2021. https://www .fao.org/documents/card/en/c/nd393en/.

FAO (Food and Agriculture Organization). 2021a. Lebanon at a glance. FAO in Lebanon. Food and Agricultural Organization of the United Nations. Accessed Aug. 18, 2021. http://www.fao.org/ lebanon/fao-in-lebanon/lebanon-at-a-glance/en/.

FAO (Food and Agriculture Organization). 2021b. Evaluation of FAO's role and work on antimicrobial resistance (AMR). Accessed Nov. 11, 2021. https://www.fao.org/evaluation/highlights/highlights -detail/en/c/1372564/.

Farhat, A. G., D. Jaalouk, and S. Francis. 2016. Adherence to the Mediterranean diet in a Lebanese sample. Nutr. Food Sci. 46:272281. https://doi.org/10.1108/NFS-09-2015-0108.

Fischer, K., K. Sjöström, A. Stiernström, and U. Emanuelson. 2019. Dairy farmers' perspectives on antibiotic use: A qualitative study. J. Dairy Sci. 102:2724-2737. https://doi.org/10.3168/jds.2018 -15015 .

Guest, G., A. Bunce, and L. Johnson. 2006. How many interviews are enough? Field Methods 18:59-82. https://doi.org/10.1177/ $1525822 \mathrm{X} 05279903$.

Harbarth, S., H. H. Balkhy, H. Goossens, V. Jarlier, J. Kluytmans, R. Laxminarayan, M. Saam, A. Van Belkum, and D. Pittet. 2015. Antimicrobial resistance: One world, one fight! Antimicrob. Resist. Infect. Control 4:49. https://doi.org/10.1186/s13756-015-0091-2.

Hmede, Z., and I. I. Kassem. 2019. First report of the plasmid-borne colistin resistance gene $(m c r-1)$ in Proteus mirabilis isolated from a toddler in non-clinical settings. IDCases 18. https://doi.org/10 .1016/j.idcr.2019.e00651.

Jones, P. J., E. A. Marier, R. B. Tranter, G. Wu, E. Watson, and C. J. Teale. 2015. Factors affecting dairy farmers' attitudes towards antimicrobial medicine usage in cattle in England and Wales. Prev. Vet. Med. 121:30-40. https://doi.org/10.1016/j.prevetmed.2015.05 .010 .

Kabrite, S., C. Bou-Mitri, J. El Hayek Fares, H. F. Hassan, and J. M. Boumosleh. 2019. Identification and dietary exposure assessment of tetracycline and penicillin residues in fluid milk, yogurt, and labneh: A cross-sectional study in Lebanon. Vet. World 12:527534. https://doi.org/10.14202/vetworld.2019.527-534.

Kassaify, Z., P. Abi Khalil, and F. Sleiman. 2013. Quantification of antibiotic residues and determination of antimicrobial resistance profiles of microorganisms isolated from bovine milk in Lebanon. Food Sci. Nutr. 4:1-9.

Lundin, J. I., D. A. Dargatz, B. A. Wagner, J. E. Lombard, A. E. Hill, S. R. Ladely, and P. J. Fedorka-Cray. 2008. Antimicrobial drug re- sistance of fecal Escherichia coli and Salmonella spp. isolates from United States dairy cows. Foodborne Pathog. Dis. 5:7-19. https:/ /doi.org/10.1089/fpd.2007.0018.

Marshall, B. M., and S. B. Levy. 2011. Food animals and antimicrobials: Impacts on human health. Clin. Microbiol. Rev. 24:718-733. https://doi.org/10.1128/CMR.00002-11.

Mays, N., and C. Pope. 2000. Assessing quality in qualitative research. BMJ 320:50-52. https://doi.org/10.1136/BMJ.320.7226.50.

Meskini, Z., N. Rechidi-sidhoum, K. Bounaama, and A. E. Dahou. 2021. Management practices on dairy cattle breeding farms in northwest of Algeria. Anim. Sci. Biotechnol. 54:237-242.

More, S. J., T. A. Clegg, and L. O'Grady. 2012. Insights into udder health and intramammary antibiotic usage on Irish dairy farms during 2003-2010. Ir. Vet. J. 65:7. https://doi.org/10.1186/2046 $-0481-65-7$.

O'Neill, A. 2021. Lebanon-Share of economic sectors in the gross domestic product 2010-2020. Accessed Aug. 18, 2021. https://www .statista.com/statistics/455263/share-of-economic-sectors-in-the -gdp-in-lebanon/.

Obaidat, M. M., A. E. Bani Salman, M. A. Davis, and A. A. Roess. 2018. Major diseases, extensive misuse, and high antimicrobial resistance of Escherichia coli in large- and small-scale dairy cattle farms in Jordan. J. Dairy Sci. 101:2324-2334. https://doi.org/10 .3168/jds.2017-13665.

Oliveira, V. H. S., I. Anneberg, H. Voss, J. T. Sørensen, and P. T. Thomsen. 2018. Attitudes of Danish dairy farmers towards biosecurity. Livest. Sci. 214:153-160. https://doi.org/10.1016/j.livsci .2018.06.004.

Osman, M., H. Al Mir, R. Rafei, F. Dabboussi, J. Y. Madec, M. Haenni, and M. Hamze. 2019. Epidemiology of antimicrobial resistance in Lebanese extra-hospital settings: An overview. J. Glob. Antimicrob. Resist. https://doi.org/10.1016/j.jgar.2018.11.019.

Ozturk, Y., S. Celik, E. Sahin, M. N. Acik, and B. Cetinkaya. 2019. Assessment of farmers' knowledge, attitudes and practices on antibiotics and antimicrobial resistance. Animals (Basel) 9. https:// doi.org/10.3390/ani9090653.

Prescott, J. F. 2019. History of antimicrobial usage in agriculture: An overview. Pages 19-27 in Antimicrobial Resistance in Bacteria of Animal Origin. ASM Press. https://doi.org/10.1128/ 9781555817534.ch2.

Prestinaci, F., P. Pezzotti, and A. Pantosti. 2015. Antimicrobial resistance: A global multifaceted phenomenon. Pathog. Glob. Health. https://doi.org/10.1179/2047773215Y.0000000030.

Raad, F., L. Nasreddine, C. Hilan, M. Bartosik, and D. Parent-Massin. 2014. Dietary exposure to aflatoxins, ochratoxin A and deoxynivalenol from a total diet study in an adult urban Lebanese population. Food Chem. Toxicol. 73:35-43. https://doi.org/10.1016/j.fct 2014.07.034.

Redding, L. E., F. Cubas-Delgado, M. D. Sammel, G. Smith, D. T. Galligan, M. Z. Levy, and S. Hennessy. 2014. The use of antibiotics on small dairy farms in rural Peru. Prev. Vet. Med. 113:88-95. https://doi.org/10.1016/j.prevetmed.2013.10.012.

Robinson, P. A. 2017. Farmers and bovine tuberculosis: Contextualising statutory disease control within everyday farming lives. J. Rural Stud. 55:168-180. https://doi.org/10.1016/j.jrurstud.2017 .08.009.

Saadeh, L. 2016. Composition of dairy potential output per year Lebanese dairy sector. Blominvest Bank 1-4. Accessed Nov. 22, 2021 https://blog.blominvestbank.com/wp-content/uploads/2016/05/ Lebanese-Dairy-Sector2.pdf.

Saini, V., J. T. McClure, D. Léger, S. Dufour, A. G. Sheldon, D. T. Scholl, and H. W. Barkema. 2012. Antimicrobial use on Canadian dairy farms. J. Dairy Sci. 95:1209-1221. https://doi.org/10.3168/ jds.2011-4527.

Speksnijder, D. C., H. Graveland, I. A. J. M. Eijck, R. W. M. Schepers, D. J. J. Heederik, T. J. M. Verheij, and J. A. Wagenaar. 2017. Effect of structural animal health planning on antimicrobial use and animal health variables in conventional dairy farming in the Netherlands. J. Dairy Sci. 100:4903-4913. https://doi.org/10.3168/jds 2016-11924. 
Swinkels, J. M., A. Hilkens, V. Zoche-Golob, V. Krömker, M. Buddiger, J. Jansen, and T. J. G. M. Lam. 2015. Social influences on the duration of antibiotic treatment of clinical mastitis in dairy cows. J. Dairy Sci. 98:2369-2380. https://doi.org/10.3168/jds.2014 -8488 .

Van Boeckel, T. P., C. Brower, M. Gilbert, B. T. Grenfell, S. A. Levin, T. P. Robinson, A. Teillant, and R. Laxminarayan. 2015. Global trends in antimicrobial use in food animals. Proc. Natl. Acad. Sci. USA 112:5649-5654. https://doi.org/10.1073/pnas.1503141112.

Virkki, T., M. Husso, M. Notko, J. Holma, A. Laitila, and M. Mäntysaari. 2015. Possibilities for intervention in domestic violence: Frame analysis of health care professionals' attitudes. J. Soc. Serv. Res. 41:6-24. https://doi.org/10.1080/01488376.2014.917449.

WHO (World Health Organization), FAO (Food and Agriculture Organization of the United Nations), and OIE (World Organisation for Animal Health). 2019. Monitoring and evaluation of the global action plan on antimicrobial resistance: Framework and recommended indicators. Accessed Nov. 11, 2021. https://apps.who.int/ iris/handle/10665/325006.
WHO (World Health Organization). 2020. Antibiotic resistance. Accessed Nov. 22, 2020. https://www.who.int/news-room/fact -sheets/detail/antibiotic-resistance.

WHO (World Health Organization). 2018. Critically Important Antimicrobials for Human Medicine. WHO. https://doi.org/978-92 $-4-151552-8$

Zhang, X. Y., L. J. Ding, and M. Z. Fan. 2009. Resistance patterns and detection of $a a c(3)-I V$ gene in apramycin-resistant Escherichia coli isolated from farm animals and farm workers in northeastern of China. Res. Vet. Sci. 87:449-454. https://doi.org/10.1016/j.rvsc 2009.05.006.

\section{ORCIDS}

Iman Dankar ำ https://orcid.org/0000-0002-6929-0419

Hussein Hassan (® https://orcid.org/0000-0003-4215-6815

Mireille Serhan @ \ttps://orcid.org/0000-0002-9695-5770 